\title{
Autobiographical Memories in Major Depressive Disorder ${ }^{\dagger}$
}

\author{
Victor Claúdio, ${ }^{1 *}$ João Garcez Aurélio ${ }^{1}$ and Paulo P. P. Machado ${ }^{2}$ \\ ${ }^{1}$ Health and Psychology Investigation Unit (UIPES), Instituto Superior de Psicologia Aplicada, Lisbon, Portugal \\ ${ }^{2}$ Psychotherapy and Psychopathology Research Unit, CIPsi, School of Psychology, University of Minho, Braga, \\ Portugal
}

\begin{abstract}
The objective of this research was to study the relation between the processing and recall of information in major depressive disorder. An autobiographical memory task was applied to 42 subjects with a diagnosis of major depressive disorder, 28 subjects with a diagnosis of panic disorder and 51 subjects without any psychological disorder. We used clinical scales for the evaluation of depression and anxiety. The results of the three groups, and both assessment periods of depressed subjects, were compared. The results indicate the existence, in severely depressed subjects, of a bias in processing and recalling negative information. We associate this situation to the existence of negative contents in selfschemas and processing and recall of information consistent with these schema contents. Based on the obtained results, we consider that the onset and maintenance of depression is more related to the information encoding and recall processes, controlled by the self's negative schemas, than with negative thoughts. Copyright $\odot 2011$ John Wiley \& Sons, Ltd.
\end{abstract}

Key Practitioner Message:

- The fact that depressed individuals predominantly recall categorical memories should alert therapists to their presence and the difficulties associated with eliciting specific memories. The importance of insisting upon a greater memory specificity as a means to interrupt the depressive bias and the importance of categorical memories as a possible diagnostic tool of severity of depression should be taken into consideration.

- A greater focus upon positive memories should be beneficial in therapy.

- An evaluation of the recall characteristics of autobiographical memories in depressed and panic patients allows for their use in the therapeutic process, in terms of the activation of such memories and the associations that can be fostered by the therapist.

- The relation between early maladaptive schemas and autobiographical memories allows for a clarification of such schemas in therapy by means of the autobiographical memories recalled.

- In a therapeutic setting, a relation can be established between autobiographical memories, attachment styles and interpersonal relations patterns, concerning panic and depressed patients.

Keywords: Autobiographical Memories, Depression

Faced with the question 'what is an autobiographical memory?', several definitions can be found. Tulving (1972) defined autobiographical memories by associating them to the knowledge preservation regarding an event, experienced by the subject, in a given context; he also differenced them from semantic memories-the representation of

* Correspondence to: Victor Claúdio, Health and Psychology Investigation Unit (UIPES), Instituto Superior de Psicologia Aplicada, Rua Jardim do Tabaco, 34, 1149-041 Lisbon, Portugal.

E-mail: uipes@ispa.pt

TThis paper is based on the dissertation research of the first author (VC), carried out at the University of Minho, under the supervision of the last author (PPM). concepts without the preservation of context. According to Barsalou (1988), autobiographical memories are composed of generic knowledge and are associated with the activities that control recall processes. For Conway (1995), the encoding and construction process of autobiographical memories has its model in the information related to the self.

Autobiographical memory is characterized by a good organization, the preservation of an event's general characteristics and the possibility of recall in the absence of a voluntary decision. Rubin, Wetzler and Nebes (1986) referred three of its specific characteristics: (a) they would be more likely to stray from the reality of the lived event because they are the individual's memories and, therefore, 
more susceptible to being transformed and reconstructed, having temporality a very important role; (b) the temporality through which the autobiographical memories extend themselves - the individual's entire life-could lead to an overlay of the aspects related to the his or her development and the aspects of the experienced event that were memorized; and (c) the autobiographical memories would be intimately related with affection, which would imply that they had a fundamental part in organizing the self, and the self would be nuclear in structuring, encoding and remembering autobiographical memories.

Searleman and Herrmann (1994) noticed that the number of autobiographical memories recalled differs in time, as was demonstrated by the work of Rubin et al. (1986). The results of their work indicated that individuals recalled more recent events and that the level of recall, of a given event, diminished in function of the time elapsed between its occurrence and the moment of recall. Peterson (1979) and Watson and Dyck (1984), from an attributional model standpoint, noticed that the oldest memories suffered an attributional change provoked by the influence of the self on those memories, thereby going from the memories of experienced situations to the memories of dispositions felt. Searleman and Herrmann (1994) also mentioned that, given the influence of temporality, one could observe differences in recall that were due to the subject's age. Childhood amnesia (Eysenck, 2009) and reminiscence (Anderson \& Conway, 1997; Conway \& Rubin, 1993; Ruíz-Vargas, 1991; Searleman \& Herrmann, 1994) would be associated with this situation.

In the process of recalling autobiographical memories, according to Reiser, Black and Kalamarides (1986), several elements have an active role: the objectives that the individual was trying to reach, what was going on at the time of the event's occurrence, what triggered it and its consequences. In a study they performed, the authors found three recall strategies.

In the first strategy, the subjects made a description of the recall context elicited by the task and, from it, referred the experience, i.e., they accessed the lived experience through a new context. This strategy assumed several forms: (a) the activities' context that allowed access to a wide range of information, the action stages, the objectives that the subject sought to accomplish with his or her actions and the causal relations between them; (b) the subject would reconstitute the event given his or her objectives at the time; (c) the subject could access the event by recalling the people who were present when it occurred; and (d) through the temporality of the event, the subject could have access to the objectives that characterized that period or to the people with whom he or she interacted at the time, thereby having two ways to recall.
In the second recall strategy, the subjects would try, unsuccessfully, to access the memory of the lived experience through a category.

Finally, in the third strategy, the subjects would evoke a different experience from the one asked but that had some resemblance.

Considering these results, we think it is important to highlight the nuclear role of temporality in the organization of autobiographical memory, as emphasized by Tulving (1972), as well as the importance of context in accessing these autobiographical memories.

This last aspect is in accordance with the model proposed by Schank (1982) and Kolodner (1983). They proposed that the subjects began by recalling the context of the event's encoding. Following this line of thought, Reiser, Black and Abelson (1985) considered that it was easier to recall an event when it was contextualized than when it was a general event. The results of their work reinforced this idea that, in accordance with Schank (1982) and Kolodner (1983), allowed to state that there exists a contextual organization of memory, which is variable. However, several events can exist in a given context, which implies that the subject would use the specific characteristics of the one he or she desired in order to separate it from others. This process's target would be the knowledge structure to which the event's encoding context corresponds.

Based on these proposals, some hypotheses regarding autobiographical memories can be elaborated. The encoding process would occur taking into account the event's relevant characteristics, searching for elements common to other events, which would allow the formation of categories, and temporally relating them. Each encoded event would be related with the subject's specific objectives. This perspective is congruent with the coding and retention models of Neisser (1986) and with the approach of Conway and Bekerian (1987).

As for recall, there are several possibilities. Barsalou (1988) considered recall a search through temporality, whereas Reiser et al. (1985) considered it a search process through context. For Williams and Dritschel (1992), it would be the establishment of objectives through the word stimulus. According to Skowronski and Walter (2004), context was fundamental for recall and that a memory narrative differed according to the recall's objective.

Hence, if the narrative's objective was a description that would allow the maintenance of the memory of a given event, the elaboration level would be smaller than it would if the narrative was made for a third person or even to oneself in order to understand a certain event.

Overall, and agreeing with Conway and Rubin (1993), we can focus on autobiographical memory's structure through recall. 


\section{AUTOBIOGRAPHICAL MEMORIES' RECALL AND DEPRESSION}

Confronted with the task of recalling a specific event triggered by a word, subjects made the mistake of giving general recalls. Hence, in Pillemer (1984) as well as in Pillemer and White's (1989) perspective, subjects did not recall a theme related to a specific event but to several events. This type of memory allows a quick and synthesized access to a wide array of information in order to perform the autobiographical memory task. According to Norman and Bobrow (1979), the generalization of autobiographical memory and its quick access to more synthesized information is adjusted to an individual's daily needs.

However, when such a generalization occurs, when faced with an autobiographical memory task, we are in the presence of a task performance error that appears in a more systematic way in some disorders, such as the emotional ones (Williams \& Dritschel, 1992). These authors distinguished two categories in these generalizations: (a) categorical memories that referred to a description of an intermediate level, which implied a less extensive memory search and which could be associated with a flaw in the supervisory attentional system and (b) extended memories, which occurred when the subject privileged originality-a memory that is not in accordance with the instructions given-instead of the temporal framework. These memories would be older, involve more individualized features and serve as a response to emotional interpretations.

The characteristics of this type of memory are similar to extensive memories by Linton $(1975,1979,1982,1986)$ and to generic memories by Brewer (1986).

According to Barsalou (1988), they work as a way of organizing autobiographical memories. Williams (1996) stated that categorical memories would be the basis for hyper general memories as, in order to access a specific memory, which describes a given time and context, it would be necessary that the categorical type of search was interrupted.

Williams and Dritschel (1992) performed two studies in which they used positive, negative and neutral words (the latter was used only in the second study) in autobiographical memory tasks, with the objective of observing the differences between categorical and extended memories, and their possible relation to the ways of encoding, retention and recalling autobiographical memories. The results of both studies indicated that (a) subjects produced more general memories when the recall is triggered by negative words; (b) the events recalled with negative words were older than those recalled with other words; however, more positive events were recalled; (c) more extended memories were observed when the recalled events were older and less frequent, and when the words had an emotional valence, either negative (the highest) or positive (higher than neutral words); (d) no differences between latency times and word valence were observed; (e) it was noted that events of a given period were recalled, independent of the valence of the stimulus word; this fact strengthened the possibility regarding the existence of a temporal structure from which the subject would build his or her search process; and (f) subjects demonstrated a preference for using one type of general memory.

In short, regarding these studies, we can claim that there are differences between the use of both types of general memory. The aspects that influence the appearance of categorical or extensive memories are (a) the subject's preference-when one type is used, the other becomes subordinated to it; (b) the valence of the words used; (c) age; and (d) the frequency of the event. Hence, extended memories would be related with older, less frequent events and with the emotional tone of the stimulus word. They would be specific memories because, in order for their resurgence to occur, the subject had to go through a discrimination process of mnesic material. In the case of categorical memories, the opposite would occur.

According to Williams and Dritschel (1992), the appearance of these categorical memories would be due to, what Shallice (1988) considered to be, a flaw in the supervisory attentional system-that would be related with the evaluation processes, strategy and objectives. The subject would not be able to discriminate the objective of his or her memory search and that would prevent him or her from recalling specific events. Several studies have supported a relation between categorical memories and the supervisory attentional system: studies of Williams and Broadbent (1986) and Williams and Dritschel (1988) comparing subjects that had attempted suicide without psychopathological disorders; work of Philips and Williams (1998) in which they observed the existence of a relation between the increase of cognitive deficit and a decrease in specific memories, in depressed elders; and observation of Goddard, Dritschel and Burton (1996) that there is a strong relation between recall of categorical memories and a marked incapacity for social problem solving, in depressed individuals. Peeters, Wessel, Merckelbach and Boon-Vermeeren (2002) observed a relation between hyper general autobiographical memories and the recall of categorical memories in depression. We could relate these results to the fact that the depressed individual is focused upon himself or herself, which would be reinforced by categorical memories, thereby limiting the possibility of attending to the environment, in order to solve situations.

As can be verified from the studies mentioned previously, one of the main effects of autobiographical memory bias, in depression, was observed in the relation between hyper general and specific memories. Depressed subjects have shown a tendency to give hyper general autobiographical memories instead of specific ones (Brittlebank, Scott, Williams, \& Ferrier, 1993; Kuyken \& Brewin, 1995; Williams \& Broadbent, 1986). 
Several other studies point in the same direction. Dalgleish, Spinks, Yierd and Kuyken (2001) found a relation between a greater recall of hyper general autobiographical memories in the presence of positive words and prediction for onset of depression in subjects with seasonal affective disorders. Leibetseder, Rohrer, Mackinger and Fartacek (2006) observed a relation between an inferior number of specific autobiographical memories, in depressed individuals, and suicide attempts. Wessel, Meeren, Peeters, Arntz and Merckelbach (2001) noted a relation between the severity of depression and the onset of a bigger number of hyper general autobiographical memories. Mackinger et al. (2004) found a predictive relation between the recall of specific memories, in the presence of positive and aggressive words, in a 65-patient sample going through alcoholic detoxification, and the remission of depressive symptoms.

Moreover, Raes et al. (2006) related the recall of hyper general autobiographical memories with difficulties in the identification of the different factors, which would allow the recognition of an event's specificity. In this study, they found a relation between vulnerability to depression and a reduced number of specific memories. This relation between autobiographical memory changes and vulnerability to depression is also stated in the work by Peeters et al. (2002). Rumination was another factor that was pointed out, by these authors, as being related to the smaller number of specific memories, recalled by depressed individuals. Ramponi, Barnard and Nimmo-Smith (2004) classified hyper generalization as a memory deficit that prevents recall of an event's specific characteristics. They too related this deficit to rumination. This relation between a bigger number of hyper general memories, in depression, and rumination has also been stated in several other studies (Raes et al., 2005; Watkins \& Teasdale, 2001, 2004; Watkins, Teasdale, \& Williams, 2000; Williams 2004; Williams et al., 2007).

These biases in the recall of autobiographical memories, in depression, could be explained by the, previously stated, idea that individuals would create a general context for the recall of autobiographical memories, from which they would search for the specific event. Depressed individuals only do the first part of the process since, by accessing a categorical description, they avoid accessing the specific event that would be associated with emotional contents.

A relation between a more frequent use of general memories and an avoidance of recalling traumatic material was also observed in depressed women who had been victims of child sexual abuse (Kuyken \& Brewin, 1995), as well as in militaries with post-traumatic stress (McNally, Lasko, Macklin, \& Pitman, 1995). Kuyken, Howell and Dalgleish (2006) realized that, in depressed teenagers, the number of hyper general autobiographical memories was lower for those that had reported the traumatic event in comparison with those who had not. Kremers, Spinhoven, Van der Does and Van Dyck (2006) noticed that in borderline individuals, with co-morbid depression, the number of hyper general autobiographical memories was superior to the number of specific memories. Another consequence has to do with the several connections established between categorical descriptions, situated at a certain level, which would allow for an interactive movement through the network of negative relations, which would become more complex, as it was conducted by a self-reference process. This process contributed to the encoding by supplying the general characteristics of events associated with the emotions that it had spurred.

Hence, instead of generating the recall of a specific event, a stimulus would lead to the activation of these connections, reinforcing the mnemonic interlock (Williams, 1992, 1996). According to Williams (1996), in the face of a request to recall a specific memory, which refers to the self, subjects recall generic memories. This phenomenon can be understood according to claims of Conway and Pleydell-Pearce (2000) and Williams (2004) of a hierarchical process at the level of specific autobiographical memory recall. This movement, which would take place in the executive or central processes, begins with a search for memories of generic events and then moves to memories of specific events. These aspects would lead depressed subjects to show, especially when recalling positive events, a more frequent recall of generic events than that showed by non-depressed individuals (Moore, Watts, \& Williams, 1988).

Overall, the use of a greater number of general memories seems to be related to the fact that depressed individuals encode their events in a general way.

According to Williams (1992), the depressed subject encodes specific events according to their affective valence. Therefore, the encoding is carried out in general schemas that represent positive and negative experiences. This form of encoding makes it difficult to access specific memories. This seems to be the encoding scenario for events with a high affective significance. This aspect, associated with the fact that depressed individuals have difficulty encoding several elements of an event that happened at the same time, implies that the affect experienced during the event is the nuclear element of the encoding. As a consequence, it is at this level that the process of self-referent material occurs. Thus, when the depressed individual accesses his or her memories by means of the encoded emotional valences, even if he or she modifies his or her mood, the recall of general memories will always be facilitated (Williams, 1992). We can therefore claim that this is more a structural limitation than an effect congruent with the mood state. 
However, mood congruency effects are also quite influential in memory, especially in depressed individuals (Baddeley, 2009; Power \& Dalgleish, 1997). Due to mood congruency effects in encoding and remembering, there is a negative bias that leads to a preference for negative information processing, which naturally, has a great influence in the autobiographical memories recalled.

\section{OBJECTIVE}

In this study, we intended to compare an autobiographical memory task with the answers given by depressed subjects, subjects with a panic disorder and subjects without psychopathological disorders. We will also compare the depressed subject's answers at two different evaluation moments in order to analyse the relation between the recall of autobiographical memories and severity of depression.

Considering autobiographical memories as being closely related to the self and taking into account the existence of a negative self model in depressed subjects, the following questions were asked. (a) Does the negative self perspective, found in depressed individuals, condition the emotional valence of the recalled autobiographical memories? (b) Does the emotional valence of the stimulus words used in the task affect the valence and type of the recalled autobiographical memory?

We considered the existence of a bias between the encoding, retention and recall of information in depressed subjects. This bias would become more severe as information became more related to the self.

Depressed subjects would also have a greater difficulty in accessing specific memories, reducing their autobiographical memories to the general memories level.

The following hypothesis were also elaborated: (a) depressed subjects would recall more negative content autobiographical memories than the other groups studied; (b) depressed subjects would recall more autobiographical memories when the stimulus word was negative, compared with when the stimulus word was positive or neutral; (c) depressed subjects would recall more autobiographical memories than the other groups when the stimulus word was negative; (d) depressed subjects would present quicker response times in negative words by comparison with positive or neutral words; and (e) depressed subjects would present a bigger number of categorical memories than extended ones, when compared with the other two groups.

We considered the same hypothesis when comparing both evaluations moments of the depressed subjects, taking into consideration the different degrees of depression.

\section{METHOD}

\section{Participants}

Subjects with a Diagnosis of Major Depressive Disorder

The sample of subjects with major depressive disorder consisted of 42 subjects: 30 subjects to which all instruments were applied and 12 subjects to which the Hamilton Rating Scales for Depression and Anxiety was not applied. The inclusion criteria for our sample were (a) having had one or more major depressive episodes; to classify the episodes, we considered the Diagnostic and Statistical Manual of Mental Disorders, Fourth Edition (DSM-IV) diagnostic criteria; (b) being without psychopharmacological medication or having had a stabilized medication for at least 3 months; (c) being able to read and write; and (d) having no marked disturbances of visual capacity. The aspects referred in points (c) and (d) were common to the other groups. The average age was 45 years, and $81 \%$ were women. Most subjects $(74 \%$ ) had been on antidepressive medication for at least 3 months.

\section{Subjects with a Diagnosis of Panic Disorder}

This sample consisted of 28 subjects: 15 to which all instruments were applied and 13 to which the Hamilton Rating Scales for Depression and Anxiety was not applied. The inclusion criteria for this sample were as follows: (a) having panic disorder (with or without agoraphobia); to classify the episodes, we considered the DSM-IV diagnostic criteria and (b) being without psychopharmacological medication or having had a stable medication for at least 3 months. The average age was 36 years, and $75 \%$ were women. $82 \%$ had been on anxiolytic medication for at least 3 months.

\section{Subjects without Psychopathological Disorders}

This sample consisted of 51 subjects. The inclusion criteria for this sample were as follows: (a) no past or recent history of psychopathological disorders and (b) no past or recent history of using psychopharmacological medication. The age average was 40 years. Female subjects represented $77 \%$ of the sample.

\section{Instruments}

\section{Autobiographical Memory Task}

In this task, 30 nouns were used, 10 positive (like happiness and loyalty), 10 negative (such as loneliness and selfishness) and 10 neutral (like floor and chair).

The nouns selected were those that presented a higher frequency in a 350-student sample, to whom this task was applied in three distinct moments. In the first moment, the students were given a blank sheet of paper containing the following instruction: 'Write down twenty nouns that you consider having positive characteristics'. In the second 
moment, after the blank sheet was collected, the students were given another one with the following instruction: 'Write down twenty nouns that you consider having negative characteristics'. In the third and final moment, after the second blank sheet was collected, the students were presented a third one with the following instruction: 'Write down twenty nouns that you consider having neutral characteristics'.

After analysing the responses, we were able to obtain the 10 most frequent used nouns for each categorypositive, negative and neutral.

The nouns were presented in a pseudorandom way, since there could never be more than two of the same valence being shown consecutively.

\section{Instruction}

Before the presentation of the first noun the subject was told 'Some words will appear on the screen. I want you to read each word attentively and tell me an event from your life that this words reminds you of. There aren't right or wrong answers since the events are different for different individuals'. Before projecting each word on screen, the subject was told 'And this word, what event of your life does it remind you of?'

\section{Noun Presentation}

The exposure time for each of the nouns was of $1 \mathrm{~min}$. The subject's answers were audio recorded after the necessary consent was given.

The nouns were presented to the subjects on a computer screen. The words were written in capitals and in black, over a white background. PowerPoint was the program used.

\section{Clinical Instruments}

The following clinical instruments were used:

1. the Portuguese version of the Hamilton Rating Scale for Depression (Hamilton, 1960), designed by Hamilton in 1957 and published, for the first time, in 1960;

2. the Portuguese version of the Beck Depression Inventory (BDI; Beck, Ward, \& Mendelson, 1961);

3. the Portuguese version of the Hamilton Rating Scale for Anxiety (Hamilton, 1959), translated by Luísa Figueira;

4. the Portuguese version of the State and Trait Anxiety Inventory (STAI; Y Form; Spielberger, 1983), translated by Américo Baptista; and

5. the Portuguese version of the Adult Sub-verbal Test of the Wechsler Scale, translated by Leandro de Almeida.

\section{Follow-up}

Three months after the first evaluation, a group of 30 individuals was evaluated. The objective of this second evaluation was to compare the two assessment moments, regarding the experimental task, and to see whether a change in the severity of depression would imply differences in autobiographical memories, since between the first and second moments, there could have been changes, due to either psychological or psychopharmacological treatment. Hence, we evaluated this group on two occasions, separated by a 3-month period. We chose this period for two reasons: (a) to allow the possibility of change in the subject's level of depression and (b) to reduce the memory effects on the evaluation tasks.

\section{RESULTS}

In the statistical analysis, whenever it was necessary to resort to multiple statistical tests, we used the Bonferroni correction, in order to reduce the possibility of error.

\section{Analysis of the Results of the Clinical Scales}

In the Hamilton Rating Scale for Depression, we observed that in the depressed individual's first evaluation, the average was 13.1 , with a standard deviation $(\mathrm{SD})=5.65$, which was significantly higher $(t(29)=2.18, p=0.037)$ than the one recorded in the second evaluation $(\mathrm{M}=10.5$, $\mathrm{SD}=5.12$ ) (see Table 1).

In the BDI, the average of the first evaluation was 19.5, with a $\mathrm{SD}=8.56$, and the average of the second evaluation was 18 , with a $\mathrm{SD}=10.43$. No significant differences between both averages were observed $(t(29)=1.05$, $p=0.304$ ) (see Table 1).

In both evaluations, a significant positive correlation was observed between both depression measures- $(p<0.05)$ with $r=40$ in the first evaluation and $(p<0.01)$ with $r=0.59$ in the second evaluation.

The three groups presented a significant difference in the BDI, $F(2,118)=39.9$, MS $=89.10, p=0.000$.

The depressed subjects presented a significantly higher severity of depression $(p<0.05)$ when compared with the subjects without psychological disorder. Regarding the subjects with a panic disorder, they also recorded a significantly higher average than those without psychological disorders $(p<0.05)$, and their average was much closer to the one of the depressed subjects (see Table 2).

In the Hamilton Rating Scale for Anxiety, the depressed subject's first evaluation average was 18.7, with a $\mathrm{SD}=6.92$, whereas the second evaluation average was 15.5 , with a $\mathrm{SD}=7.50$. The difference between both averages was significant $(t(29)=3.96, p=0.000$ ) (see Table 1).

In both evaluations, the STAI State score had a significantly higher average in the first evaluation $(\mathrm{M}=60.2$ and $\mathrm{SD}=0.91, t(29)=4.15, p=0.000)$ and in the 
Table 1. Averages, standard deviation and significance of the differences in averages between depressed subject's first and second moments of evaluation, regarding Hamilton Rating Scale for Depression, Beck Depression Inventory, Hamilton Rating Scale for Anxiety, State and Trait Anxiety Inventory State and State and Trait Anxiety Inventory Trait

\begin{tabular}{|c|c|c|c|c|c|c|c|}
\hline & \multicolumn{2}{|c|}{ Depressed } & \multicolumn{2}{|c|}{ Depressed } & $t$ & $\mathrm{df}$ & $p$ \\
\hline & \multicolumn{2}{|c|}{ First evaluation } & \multicolumn{2}{|c|}{ Second evaluation } & & & \\
\hline & \multicolumn{2}{|c|}{$n=30$} & \multicolumn{2}{|c|}{$n=30$} & & & \\
\hline & A & SD & A & SD & & & \\
\hline Hamilton Depression Rating Scale & 13.1 & 5.65 & 10.5 & 5.12 & 2.18 & 29 & $0.037^{*}$ \\
\hline BDI & 19.5 & 8.56 & 18.0 & 10.43 & 1.05 & 29 & 0.304 \\
\hline Hamilton Anxiety Rating Scale & 18.7 & 6.92 & 15.5 & 7.50 & 3.96 & 29 & $0.000^{*}$ \\
\hline STAI State & $58.3^{+}$ & 11.42 & $53.6^{\ddagger}$ & 10.49 & 2.70 & 29 & $0.011^{*}$ \\
\hline STAI Trait & $48.3^{+}$ & 12.50 & $46.6^{\ddagger}$ & 12.21 & 0.916 & 29 & 0.367 \\
\hline
\end{tabular}

$\mathrm{BDI}=$ Beck Depression Inventory. $\mathrm{df}=$ degrees of freedom. $\mathrm{SD}=$ standard deviation. STAI = State and Trait Anxiety Inventory.

* Significant difference between the averages of both groups.

${ }^{+} t(29)=4.14, p=0.000$.

${ }^{\ddagger} t(29)=2,59, p=0.015$.

Table 2. Averages, standard deviation and significance of the differences between averages of depressed subjects (depressed), panic disorder subjects (panic) and no psychopathological disturbance subjects (normal) in Hamilton Rating Scale for Depression, Beck Depression Inventory, Hamilton Rating Scale for Anxiety, State and Trait Anxiety Inventory State and State and Trait Anxiety Inventory Trait

\begin{tabular}{|c|c|c|c|c|c|c|c|c|c|c|}
\hline & \multirow{2}{*}{\multicolumn{2}{|c|}{$\begin{array}{c}\text { Depressed } \\
n=42\end{array}$}} & \multirow{2}{*}{\multicolumn{2}{|c|}{$\begin{array}{l}\text { Panic } \\
n=28\end{array}$}} & \multirow{2}{*}{\multicolumn{2}{|c|}{$\begin{array}{c}\text { Normal } \\
n=51\end{array}$}} & \multirow[t]{3}{*}{$F$} & \multirow[t]{3}{*}{$\mathrm{df}$} & \multirow[t]{3}{*}{ MS } & \multirow[t]{3}{*}{$p$} \\
\hline & & & & & & & & & & \\
\hline & $\mathrm{M}$ & $\overline{S D}$ & $\mathrm{M}$ & SD & $\mathrm{M}$ & SD & & & & \\
\hline BDI & $23.9^{* *}$ & 1.52 & $15.2^{* *}$ & 10.88 & $6.4^{* *}$ & 6.12 & $39.9 *$ & 2,118 & 89.10 & 0.000 \\
\hline STAI State & $60.2^{* *}$ & 0.91 & $51.3^{* *}$ & 10.63 & $36.6^{* *}$ & 10.39 & $57.3^{*}$ & 2,118 & 113.14 & 0.000 \\
\hline STAI Trait & $53.9^{* *}$ & 4.37 & $44.8^{* *}$ & 9.32 & $35.7^{* *}$ & 10.39 & $28.0^{*}$ & 2,118 & 135.72 & 0.000 \\
\hline
\end{tabular}

$\mathrm{BDI}=$ Beck Depression Inventory. $\mathrm{df}=$ degrees of freedom. $\mathrm{SD}=$ standard deviation. STAI = State and Trait Anxiety Inventory.

* Significant difference $(p<0.05)$ in the ANOVA between the three groups.

** Significant difference $(p<0.05)$ in Tukey test between both groups in a given factor.

second evaluation $(M=51.3$ and $\mathrm{SD}=10.63, t(29)=2.59$, $p=0.015$ ) when compared with the STAI Trait score (first evaluation: $\mathrm{M}=53.9$ and $\mathrm{SD}=4.37$; second evaluation: $\mathrm{M}=44.8$ and $\mathrm{SD}=9.32$ ) (see Table 1 ).

In the first evaluation, the STAI State score had significantly higher averages, $(t(29)=2.70, p=0.011)$ when compared with the second evaluation (see Table 1).

The averages of STAI Trait, in both evaluations (first evaluation: $\mathrm{M}=53.9$ and $\mathrm{SD}=4.37$; second evaluation: $\mathrm{M}=44.8$ and $\mathrm{SD}=9.32)$, did not show significant differences, $t(29)=0.916, p=0.367$ (see Table 1).

Depressed subjects presented STAI State and Trait values that were significantly higher $(p<0.05)$ than the ones recorded by subjects with panic disorder and by those with no disorders. The latter presented significantly lower scores $(p<0.05)$ in both scales, when compared with the panic disorder group (see Table 2).
In both evaluations of the depressed subject, a significant correlation $(p<0.05)$ was found between STAI Trait and Hamilton Rating Scale for Anxiety- $r=0.48$ in the first evaluation and $r=0.40$ in the second evaluation-that was not found between this scale and the STAI State, for any of the evaluations.

The groups studied did not present significant differences in their Wechsler Adult Intelligence Scale Vocabulary Subtest, $F(2,118)=2.72, \mathrm{MS}=93.26, p=0.070$.

\section{Analysis of the Results of the Autobiographical Memory Task}

Analysis of the Total of Events Recalled

Observing the comparison between both evaluations of the depressed subjects (see Table 3), we noticed, in the first evaluation, a total events' average $(M=26.1$ and $S D=11.25$ ) greater than the one registered in 
Table 3. Averages, standard deviation and significance of the factors of analysis of the autobiographical memory task in depressed patients (depressed) in the first and second evaluations

\begin{tabular}{|c|c|c|c|c|c|c|c|}
\hline & & & & & $t$ & $\mathrm{df}$ & $p$ \\
\hline & First & ation & Secol & ration & & & \\
\hline & & & & & & & \\
\hline & A & SD & A & SD & & & \\
\hline Total events recalled & 26.1 & 11.25 & 24.2 & 10.18 & 1.54 & 29 & 0.134 \\
\hline Total of negative events recalled & $15.5^{+}$ & 7.36 & $14.6^{\S}$ & 6.75 & 0.903 & 29 & 0.374 \\
\hline Total of positive events recalled & $8.6^{+}$ & 4.59 & $8.1^{\S}$ & 4.60 & 0.839 & 29 & 0.408 \\
\hline Total events recalled with negative words & $10.6^{\ddagger}$ & 6.93 & 9.5 & 6.39 & 1.96 & 29 & 0.060 \\
\hline Total events recalled with positive words & 8.2 & 4.27 & 7.4 & 3.42 & 1.41 & 29 & 0.168 \\
\hline Total events recalled with neutral words & $7.3^{\ddagger}$ & 3.22 & 7.4 & 3.68 & -0.210 & 29 & 0.835 \\
\hline Latency time in negative words & 66.5 & 41.12 & 55.7 & 39.75 & 1.83 & 29 & 0.077 \\
\hline Latency time in positive words & 69.2 & 49.77 & 60.1 & 45.10 & 1.02 & 29 & 0.314 \\
\hline Latency time in neutral words & 59.0 & 40.82 & 60.7 & 51.03 & -0.179 & 29 & 0.859 \\
\hline
\end{tabular}

$\mathrm{df}=$ degrees of freedom. $\mathrm{SD}=$ standard deviation

${ }^{+} t(29)=-5.17, p=0.000$.

${ }_{t} t(29)=2.68, p=0.012$.

$\S_{t(29)}=-4.83, p=0.000$.

Table 4. Averages, standard deviation and significance of the analysis factors of the autobiographical memory task in subjects with a diagnosis of major depressive disorder (depressed), subjects with a panic disorder (panic) and subjects without psychological disorder (normal)

\begin{tabular}{|c|c|c|c|c|c|c|}
\hline & \multicolumn{2}{|c|}{ Depressed } & \multicolumn{2}{|c|}{ Panic } & \multicolumn{2}{|c|}{ Normal } \\
\hline & \multicolumn{2}{|c|}{$n=42$} & \multicolumn{2}{|c|}{$n=28$} & \multicolumn{2}{|c|}{$n=51$} \\
\hline & $\mathrm{A}$ & SD & $\mathrm{A}$ & SD & $\mathrm{A}$ & $\overline{S D}$ \\
\hline Total events recalled & 22.9 & 12.46 & 19.2 & 7.83 & 19.0 & 6.79 \\
\hline Total of negative events recalled & $13.7^{\dagger}$ & 7.83 & $12.1^{\S}$ & 4.70 & $10.8^{++}$ & 4.86 \\
\hline Total of positive events recalled & $8.0^{+}$ & 5.06 & $7.0^{\S}$ & 4.22 & $8.1^{++}$ & 3.51 \\
\hline Total events recalled in negative words & $9.1^{\ddagger}$ & 6.89 & $7.4^{\mathbb{I I}}$ & 2.92 & $6.9^{\text {辝 }}$ & 2.85 \\
\hline Total events recalled in positive words & $7.1^{\ddagger}$ & 4.57 & 6.4 & 3.37 & $6.0^{\text {却 }}$ & 3.17 \\
\hline Total events recalled in neutral words & $6.6^{\ddagger}$ & 3.47 & $5.4^{\mathrm{II}}$ & 3.11 & 6.1 & 2.54 \\
\hline Latency time in negative words & $56.9^{*}$ & 39.19 & $32.3^{*}$ & 28.69 & $35.3^{*}$ & 38.63 \\
\hline Latency time in positive words & $59.0^{*}$ & 48.10 & $32.0^{*}$ & 29.94 & $31.7^{*}$ & 38.11 \\
\hline Latency time in neutral words & $53.0^{*}$ & 39.15 & $26.6^{*}$ & 27.48 & $28.7^{*}$ & 29.68 \\
\hline
\end{tabular}

Significant difference $(p<0.05)$ in the Student's $t$ test between different factors of the same group.

${ }^{+} t(41)=-5.35, p=0.000$.

$\ddagger_{t}(41)=2.06, p=0.46$.

$\S_{t}(41)=2.59, p=0.013$

$\mathbb{I I}_{t}(27)=-6.28, p=0.000$.

${ }^{++} t(27)=-4.69, p=0.000$.

$\ddagger_{t}(49)=-3.36, p=0.002$.

*Significant difference $(p<0.05)$ in the Tukey test between different pairs of groups in a given factor.

the second evaluation $(\mathrm{M}=24.2$ and $\mathrm{SD}=10.18)$. However, this difference was not significant, $t(29)=1.54$, $p=0.134$.

As can be observed in Table 4, depressed subjects presented a total recalled events' average $(M=22.9$ and $\mathrm{SD}=12.46)$ superior to the one recorded by subjects with panic disorder $(\mathrm{M}=19.2$ and $\mathrm{SD}=7.83)$ and by subjects without psychological disorders $(\mathrm{M}=19.0$ and
$\mathrm{SD}=6.79)$. However, the differences between the three groups were also not significant $(F(2,118)=2.30$, $\mathrm{MS}=$ 87.55, $p=0.105)$.

\section{Analysis of the Valence of Recalled Events}

Comparing both evaluations of depressed subjects (see Table 3), we observed that in both evaluations, the averages of negative events recalled (first evaluation: 
$\mathrm{M}=15.5$ and $\mathrm{SD}=7.36$; second evaluation: $\mathrm{M}=14.6$ and $\mathrm{SD}=6.75$ ) were significantly superior to the averages of positive events (first evaluation: $\mathrm{M}=8.6$ and $\mathrm{SD}=4.59$; second evaluation: $\mathrm{M}=8.1$ and $\mathrm{SD}=4.60, t(29)=5.17$, $p=0.000$ and $t(29)=-4.83, p=0.000)$. In the first evaluation, the average of negative recalled events was higher than in the second evaluation, whereas the average of positive recalled events was quite similar in both evaluations. In either case, the difference in averages was not significant, $t(29)=0.903, p=0.374$ and $t(29)=0.839$, $p=0.408$.

In all groups, the average of negative recalled events was significantly superior in comparison with positive recalled events, $t(41)=-5.35, p=0.000$ in depressed subjects, $t(27)=-6.28, p=0.000$ in panic disorder subjects, $t(49)=-3.36, p=0.002$ in subjects without psychological disorders (see Table 4).

In depressed subjects, the average of negative events recalled was $13.7(\mathrm{SD}=7.83)$, whereas the average of positive events recalled was $8.0(\mathrm{SD}=5.06)$ (see Table 4).

In panic disorder subjects, the average of negative events recalled was $12.1(\mathrm{SD}=4.70)$ and $7.0(\mathrm{SD}=4.22)$ for the positive ones (see Table 4).

In subjects without psychological disorders, the average of negative events recalled was $10.8(\mathrm{SD}=4.86)$, and the average of positive events recalled was $8.1(\mathrm{SD}=3.51)$ (see Table 4).

From the intergroup comparisons, we can see that there were no significant differences $(p>0.05)$ between different groups regarding the recall of positive and negative events (positive events: $F(2,118)=0.62, \mathrm{MS}=18.26$, $p=0.538$; negative events: $F(2,118)=2.80, \mathrm{MS}=36.34$, $p=0.065$ ) (see Table 4).

Analysis of the Events Recalled by Grouping the Words in Accordance to Their Valence

For this analysis, we grouped the stimulus words according to their valence-negative, positive and neutral. Afterwards, we compared the results concerning the recall of events and the latency times.

Negative words. In the depressed patient's first evaluation, the average of recalled events with negative words $(\mathrm{M}=10.6$ and $\mathrm{SD}=6.93)$ was significantly higher, $t(29)=2.68, p=0.012$, than the average of the events recalled with neutral words $(\mathrm{M}=7.3$ and $\mathrm{SD}=3.22)$ (see Table 3).

The averages of events recalled with negative and positive words were not significantly different $(t(29)=1.82$, $p=0.079$ ) (see Table 3).

In the depressed patients' second evaluation, the average of events recalled with negative words, 9.5 $(\mathrm{SD}=6.39)$, was not significantly different from the averages observed in the two other sets of words (positive: $t(29)=1.65, p=0.110$; neutral: $t(29)=1.64$, $p=0.112$ ) (see Table 3).

The averages, regarding the depressed patients, did not differ significantly between both evaluation moments $(t(29)=1.96, p=0.060)$ (see Table 3). However, the average registered in the first evaluation $(M=10.6$ and $S D=6.93)$ was superior to the one registered in the second evaluation $(\mathrm{M}=9.5$ and $\mathrm{SD}=6.39)$.

Negative words were the ones that led to a greater recall of events in all groups (see Table 4). The averages of events recalled by these words were significantly higher in the following cases $(p<0.05)$ : (a) in depressed subjects $(M=9.1$ and $\mathrm{SD}=6.89$ ) in relation to the average of events recalled with positive words $(\mathrm{M}=7.1$ and $\mathrm{SD}=4.57), t(41)=2.06$, $p=0.046$ and neutral words $(\mathrm{M}=6.6$ and $\mathrm{SD}=3.47)$, $t(41)=2.59, p=0.013$; (b) in subjects with panic disorder $(\mathrm{M}=7.4$ and $\mathrm{SD}=2.92)$ in relation to the average of events recalled with neutral words $(\mathrm{M}=5.4$ and $\mathrm{SD}=3.11)$, $t(27)=6.28, p=0.000$; and (c) in subjects without psychological disorders $(\mathrm{M}=6.9$ and $\mathrm{SD}=2.85)$ regarding the average of events recalled with positive words $(\mathrm{M}=6.0$ and $\mathrm{SD}=3.17), t(49)=3.24, p=0.002$ (see Table 4).

In a comparison analysis between groups, we observed that, although depressed subjects presented a superior average, the three groups did not present significant differences among themselves in the recall of events with negative words, $(F(2,118)=2.62, \mathrm{MS}=21.89, p=0.077)$ (see Table 4).

Positive words. Comparing the depressed subjects in both evaluative times, we noticed that in the first evaluation, the average was $8.2(\mathrm{SD}=4.27)$, whereas in the second evaluation, it was lower $(\mathrm{M}=7.4$ and $\mathrm{SD}=3.42)$. This difference was not significant, $t(29)=1.41, p=0.168$ (see Table 3).

The depressed subjects had an average of $7.1(\mathrm{SD}=4.57)$ (see Table 4). This result, despite being higher than the ones observed in subjects with panic disorder $(\mathrm{M}=6.4$ and $\mathrm{SD}=3.37)$ and in subjects without psychological disorders $(\mathrm{M}=6.0$ and $\mathrm{SD}=3.17)$, was not significantly different $(F(2,118)=1.08, \mathrm{MS}=14.11, p=0.341)$.

Neutral words. The average results of depressed individuals were very similar in both evaluation periods, as in the first evaluation, the average was $7.3(\mathrm{SD}=3.22)$ and in the second, it was $7.4(\mathrm{SD}=3.68)$ (see Table 3).

The depressed subject's average $(M=6.6$ and $S D=3.47)$ was higher than the one observed in subjects with panic disorder $(\mathrm{M}=5.4$ and $\mathrm{SD}=3.11)$ and close to the one registered by subjects without psychological disorders $(\mathrm{M}=6.1$ and $\mathrm{SD}=2.54)$ (see Table 4). However, between the three groups, there were no significant differences, $F(2,118)=1.52, \mathrm{MS}=9.15, p=0.223$.

Latency times for negative words. In the depressed patients' first evaluation, the average registered $(M=66.5$ and 
$\mathrm{SD}=41.12)$, although superior to the one in the second evaluation ( $M=55.7$ and $S D=39.75)$, was not significantly different, $t(29)=1.83, p=0.077$ (see Table 3).

The latency time's average in depressed subjects $(\mathrm{M}=56.9$ and $\mathrm{SD}=39.19)$ was significantly longer $(p<0.05)$ than the one observed in subjects with panic disorder $(\mathrm{M}=32.3$ and $\mathrm{SD}=28.69)$ and in subjects without psychological disorders $(\mathrm{M}=35.3$ and $\mathrm{SD}=38.63$ ) (see Table 4). Between the last two groups, there were no significant differences $(p>0.05)$.

Latency times for positive words. Comparing both evaluations of depressed subjects, we noticed that, although the averages did not differ significantly $(t(29)=1.02$, $p=0.314)$, the first evaluation $(\mathrm{M}=69.2$ and $\mathrm{SD}=49.77)$ had a higher average than the second evaluation $(\mathrm{M}=60.1$ and $\mathrm{SD}=45.10$ ) (see Table 3).

The depressed subjects presented an average latency time $(M=59.0$ and $S D=48.10)$ significantly longer $(p<0.05)$ than the one observed in subjects with panic disorder $(M=32.0$ and $S D=29.94)$ and in subjects without psychological disorders $(\mathrm{M}=31.7$ and $\mathrm{SD}=38.11$ ) (see Table 4).

Latency times for neutral words. In the depressed patients' second evaluation, the average $(\mathrm{M}=60.7$ and $\mathrm{SD}=51.03)$ was higher than that in the first evaluation $(\mathrm{M}=59.0$ and $\mathrm{SD}=40.82)$, although the difference did not prove to be significant, $t(29)=-0.179, p=0.859$ (see Table 3).

Also, the depressed patients' average $(\mathrm{M}=53.0$ and $\mathrm{SD}=39.15)$ was significantly higher $(p<0.05)$ than the averages of subjects with panic disorder and subjects without psychological disorders $(26.6[\mathrm{SD}=27.48]$ and 28.7 [SD $=29.68]$, respectively) (see Table 4 ).

\section{Analysis of Categorical and Extended Memories}

In the depressed subjects' first evaluation, we noticed that in $70 \%$ of the words, they recalled 'categorical memories'. In their second evaluation, they recalled 'categorical memories' in $67 \%$ of the words.

Depressed subjects, in most words $(76.7 \%)$, recalled more 'categorical memories' than 'extended memories'. Individuals with panic disorder recalled, in most words $(60 \%)$, 'extended memories'. Furthermore, subjects without any psychological disorders recalled 'categorical memories' and 'extended memories' with exactly the same number of words, 12 .

\section{Analysis of Latency Times per Words}

Regarding each word's latency time, it is important to state that the time limits considered for depressed subjects $(\geq 6.0$ and $\leq 4.0)$ were different from those given to subjects with panic disorder $(\geq 5.0$ and $\leq 2.0)$ and without psychological disorders $(\geq 4.0$ and $\leq 2.0)$. This difference revealed that depressed subjects presented longer latency times when compared with the subjects of the two other groups.

The depressed subjects presented a higher number of words with longer latency times, with a total of 10 words (four negative, four positive and two neutral), followed by the subjects without psychological disorders, with a total of five words (three negative, one positive and one neutral), and, finally, the subjects with a panic disorder, who only registered three words, one of each valence.

In depressed subjects and in subjects without psychological disorders, we observed that some words presented a longer latency time and, simultaneously, higher averages of event recall. In this situation, both groups registered two negative words and a positive one. In subjects with panic disorder, this relation was not established with any word.

Between both evaluations of depressed subjects, there were differences. Thus, in the first evaluation, there were 19 words with higher latency time averages (nine of negative valence, six of positive valence and four neutral), whereas in the second evaluation, there were fourteen words (three negative, six positive and five neutral). Hence, unlike what happened in the first evaluation, in the second, the number of negative words was inferior to the ones with other valences.

The group that registered more words with a lower latency time was the panic disorder one. They registered seven words (one of negative valence, one of positive valence and five neutral), whereas the depressed subjects and the ones without psychological disorders registered two words (one negative and one neutral).

In the case of these two groups, both words belonged to the group of words that had a lower average of event recall. This fact could be associated with the kind of answers triggered by these words, in which subjects rapidly responded, e.g., 'I can't recall any event'.

\section{Analysis by Events}

The depressed subjects recalled more events than any other group in this study. In the first evaluation, the depressed subjects' average for event recall was superior to the one shown in the second evaluation. However, the differences were not significant $(p>0.05)$.

Comparing the event recall averages according to their valence, we noticed that depressed subjects, as well as panic disorder subjects and the ones without psychological disorders, recalled significantly more negative events than positive ones $(p<0.05)$. The three groups did not present significant differences, among themselves, 
regarding the event recall averages of positive and negative events. This result led to the rejection of our first hypothesis, which stated that depressed individuals would recall more negative autobiographical memories than subjects from the other groups. However, depressed subjects did present the highest average of negative events' recall, followed by subjects with panic disorder and subjects without psychological disorders. As for positive events, depressed subjects and those without psychological disorders presented similar averages, both superior to the ones presented by individuals with panic disorder. These results indicate that depressed subjects recall more events and, preferentially, negative ones. Thus, the difference between the depressed participants and the participants without psychological disorders is related to the ease with which the former recall negative life events and not with the processing of positive information.

In the depressed patients' evaluations, we also observed a significantly superior average of negative event recall compared with positive recall. In the first evaluation, the average of negative events recalled was higher than the one registered in the second evaluation. In the positive events, no such difference was found. These results reinforce what we previously stated when we mentioned that the ease of negative event recall would be related with the severity of depression.

\section{Word Valence Analysis}

The negative words allowed for higher event recall averages in all groups.

In depressed subjects, the average of events recalled with negative words was significantly superior to the recall average with words from another valence, whereas in panic disorder subjects, this only occurred regarding the neutral words and in subjects without psychological disorders, regarding positive words. The results obtained by depressed subjects confirmed our second hypothesis, which suggested that depressed subjects would recall more autobiographical memories when the stimulus word was negative than when it was positive or neutral.

In the depressed subjects' group, the negative and positive words had a higher event recall averages than in any other group. However, there was no significant difference, which led to the rejection of our third hypothesis, in which we stated that depressed subjects would recall significantly more autobiographic memories with negative stimulus words when compared with the other subjects. However, the results did indicate that depressed subjects showed a preference for processing and recalling information with negative characteristics, as we had defended.
Regarding neutral words, depressed subjects and those without psychological disorders presented similar event recall averages, being that panic disorder subjects presented lower ones. This result is in accordance with what was stated in the previous paragraph.

In the depressed subjects' first evaluation, we noted a significantly higher event recall average with negative words by comparison with neutral words. Thus, depressed subjects presented the same valence relation as the panic disorder ones.

In the second evaluation, no significant differences were observed. In comparison with the first evaluation, the event recall averages were superior in negative and positive words and similar in neutral words. Again, the role of depression severity in the processing and recall of negative information was observed.

Depressed subjects presented significantly higher latency times when compared with the other groups in any of the word valences-negative, positive and neutral. This fact could be related with the characteristic cognitive slowing of depressed subjects. They presented a longer latency time with positive words, whereas subjects without psychological disorders presented longer latency times regarding negative words. However, the differences were not significant in either case. Being so, the depressed subjects' results rejected our fourth hypothesis, which stated that depressed subjects would present quicker response times for negative words when compared with the ones presented in positive and neutral words. However, the results did suggest a bigger difficulty for depressed subjects to recall events stimulated by positive words, i.e., they would have more difficulties processing positive information and thereby searching and recalling life events of this valence. In subjects without psychological disorders, the opposite occurs, i.e., they respond quicker to a positive stimulation than to a negative one. This reinforces the hypothesis stating that in depressed subjects, there is a bigger difficulty in processing and recalling positive information and, simultaneously, a bigger ease when these processes face negative information. In subjects with panic disorder, the latency time averages were similar in both valences. All groups recorded lower averages in face of neutral words. However, the fact that depressed subjects recorded a significantly higher average when compared with the others reinforced our belief in the existence of a cognitive slowing.

In the depressed subjects' first evaluation, the latency time average for positive and negative words was longer than the one recorded in the second evaluation. As for the neutral words, the relation was the opposite. Despite this, the differences were not significant $(p \geq 0.05)$ (see Table 3$)$. This result showed the nonexistence of a relation between latency time and depression severity. 
Depressed subjects used categorical memories more often than extended ones, with the opposite occurring in individuals with panic disorder. Subjects without psychological disorders presented exactly the same values for both memory types. This result confirmed our fifth hypothesis, which stated that depressed subjects would recall more categorical memories than extended ones when compared with the other groups. In both evaluations of the depressed subjects, they recalled more categorical memories than extended ones. This result, together with the one registered in our enlarged sample of depressed subjects, seems to clearly state that depressed subjects tend to use categorical memories. According to Williams and Dritschel (1992), these memories are associated with a less extensive search of memory material and a flaw in the supervisory attentional system (Shallice, 1988), which would make the process of searching for mnesic material more difficult, creating additional difficulties in accessing the second moment in memory hierarchy, referred by Conway and PleydellPearce (2000) and Williams (2004). The results that we found are congruent with the previously referred studies.

To systematize the results obtained by the different groups and by the depressed subjects in both evaluations, we have chosen to synthesize the most relevant ones.

\section{Synthesis of the Results}

\section{Depressed Subjects}

1. They recalled more events in more words, with a predominance in the negative words.

2. They presented higher latency times in more words. There was a relation, in some words, between the latency times presented and a superior event recall.

3. It was the group that recalled more events.

4. It was the group that presented a higher recall average of negative events.

5. They recalled significantly more negative than positive events.

6. It was the group that recalled more events with negative words.

7. They recalled significantly more events with negative words than with positive or neutral ones.

8. In the three groups of different word valence (positive, negative and neutral), they presented significantly higher latency times when compared with the two other groups.

9. They used more categorical than extended memories.

\section{Subjects with Panic Disorder}

1. They recalled events in the same number of words as subjects without psychological disorders.
2. It was the group that recorded higher latency times in a lower number of words.

3. They had an inferior event recall average, when compared with depressed subjects, and an almost equal one to the subjects without psychological disorders.

4. They presented an inferior negative event recall average in comparison with depressed subjects.

5. They recalled significantly more negative than positive events.

6. They recalled more events with negative words than the subjects without psychological disorders.

7. They recalled significantly more events with negative than with neutral words. They also recalled more events with negative than with positive words, but the difference was not significant.

\section{Subjects without Psychological Disorders}

1. They recalled more events in the same number of words as the panic disorder subjects.

2. They presented higher latency times in lesser words than the depressed subjects but in more words than the panic disorder subjects. In some words, a relation between these times and a superior event recall existed.

3. They had an event recall average nearly identical to that of the panic disorder subjects.

4. Although they had a significantly superior negative event recall average, in comparison with positive event recall average, their negative event recall average was the lowest of the three groups.

5. They had the smallest average, of the three groups, regarding negative words event recall.

6. They significantly recalled more events with negative words by comparison with positive ones.

\section{Depressed Subjects' First Evaluation}

1. Their profile regarding the recall of events in different words was similar to the one shown in the enlarged sample of depressed subjects.

2. They presented a greater number of words with high latency times than they did in the second evaluation, with a special incidence on negative words and with a strong relation to the words that had bigger event recall.

3. They had a superior event recall average when compared with that in the second evaluation and in the enlarged sample of depressed subjects.

4. They recalled significantly more negative than positive events.

5. They presented a negative event recall average superior to the one in the second evaluation. 
6. They recalled significantly more events with negative words than with neutral ones. They also recalled more events with negative than with positive words, although the difference here was not significant.

\section{Depressed Subjects' second Evaluation}

1. They presented a relation between event recall in different words that was similar to the one registered in the first evaluation and in the enlarged sample of depressed subjects.

2. They recorded higher latency times, especially in positive words.

3. They recalled significantly more negative than positive events.

4. They presented a negative words event recall average superior to the one registered in positive and neutral words. The event recall averages with positive and neutral words were identical.

\section{DISCUSSION}

The results demonstrate the existence, in depressed subjects, of a predominant processing, retention and recall of negative information. These aspects are related, according to some theoretical models, with a reinforcement of negative emotions. In depressed subjects, the preferential recall of negative events allows the maintenance and reinforcement of negative emotions, such as sadness, that are associated with the loss of valued objectives or with the impossibility to attain such valued goals.

Our results are also congruent with the relation between emotions and self-schema contents. Thus, in depressed patients, a given negative emotion stops being related only to the situation that triggered it, and would become more general, and congruent with the schema. The results illustrate this generalization of the preference for processing and recalling negative information, independent of the stimulus words presented, which demonstrates the existence, in the depressed subject, of a negative content self-schema. This schema would imply an information processing environment congruent with its negative valence. We can consider these aspects as an explanation for the recall of negative events with words from different valences, as was observed in depressed subjects. These studies also reinforce what was stated by the Interacting Cognitive Subsystems model (Teasdale \& Barnard, 1993) regarding the activation of a previously existing schematic model, which was triggered by the information processing that was, somehow, related to it.

The decrease in positive information recall and processing either through less frequent recall or through a cognitive slowing that allows the maintenance of negative information is also consistent with the existence of negative self-schemas that impair the information processing of discordant emotional valences. Because autobiographical memories are related to the self, there is a possible justification for the depressed subjects' greater number of recalled events and the predominance of negative events among those that are recalled.

Our results also show that we cannot focus on depressive memory deficits in only one way, since there is a variability associated with the depression's severity. Hence, when the depression is less severe, the subjects would not manifest memory deficit characteristics, such as negative bias and cognitive slowing. In these cases, our results show that depressed subjects show a similar profile to the one presented by subjects without psychopathological disorders, in terms of information processing and recall.

By interpreting the results of our study, we are led to question negative thoughts as responsible for the onset of depression. We believe that the onset and maintenance of depression is intimately related to the information encoding process and later recall, given the negative contents of the self's schemas. This factor could also lead to vulnerability for depression. We believe that these factors should be taken into account in the conceptualization process and psychotherapeutic intervention.

We consider that it is fundamental to work with the depressed subjects' capacity to process and recall positive information. We think that one of the possible ways to do so is by modifying the encoding process, thereby allowing for the repair of negative information processing and recall, and of negative content of the self-schemas.

We believe that these should be core aspects in the psychotherapeutic process of depressed individuals. Also, the intervention directed to the ambivalent self, which we observed in depressed patients, may enable the integration of the positive aspects of the self in the process of encoding and recalling information, thus enabling the repair process of the implications of negative information in the recalling of depressed patients.

With the objective of a better understanding of the relations between depression and memory processes, we propose that future investigations focus on comparing subjects with major depressive disorder with those with other psychopathology. The use of experimental tasks in a bigger sample of subjects with major depressive disorder and no medication, and the existence of a follow-up after a cognitive psychotherapy treatment, are important aspects to explore.

We also believe that the relations between autobiographical memory, early maladaptive schemas, styles of attachment and interpersonal relationships should be taken into account. These relations may allow a more robust understanding of the several factors that can influence the encoding and recall process and, consequently, the 
origin and maintenance of depression, thus allowing a more effective psychotherapeutic intervention.

We propose that future investigations focus on comparing participants with major depressive disorder with those with other psychopathologies so that we can better understand the relations between depression and memory processes. The use of experimental tasks in a larger sample of participants with major depressive disorder and no medication, and the existence of a follow-up after a cognitive psychotherapy treatment, are important aspects to explore.

\section{REFERENCES}

Anderson, S.J., \& Conway, M.A. (1997). Representations of autobiographical memories. In M.A. Conway (Ed.), Cognitive Models of Memory (pp. 217-244). Hove: Psychology Press.

Baddeley, A. (2009). Autobiographical memory. In A. Baddeley, M.W. Eysenck, \& M.C. Anderson (Eds), Memory (pp. 137-161). Hove: Psychology Press.

Barsalou, L.W. (1988). The content and organization of autobiographical memories. In U. Neisser, \& E. Winograd (Eds), Remembering Reconsidered: Ecological and Traditional Approaches to the Study (pp. 193-243). New York: Cambridge University Press.

Beck, A.T., Ward, C., Mendelson, M. (1961). Beck Depression Inventory (BDI). Archives of General Psychiatry, 4, 561-571.

Brewer, W.F. (1986). What is autobiographical memory? In D.C. Rubin (Ed.), Autobiographical Memory (pp. 25-49). New York: Cambridge University Press.

Brittlebank, A.D., Scott, J., Williams, J.M.G., \& Ferrier, I.N. (1993). Autobiographical memory in depression: State or trait marker? The British Journal of Psychiatry, 162, 118-121.

Conway, M.A. (1995). Autobiographical memories and autobiographical knowledge. In D.C. Rubin (Ed.), The Construction of Autobiographical Memory. New York: Cambridge University Press.

Conway, M.A., \& Bekerian, D.A. (1987). Organization in autobiographical memory. Memory and Cognition, 15(2), 119-132.

Conway, M.A., \& Pleydell-Pearce, C.W. (2000). The construction of autobiographical memories in the self-memory system. Psychological Review, 107, 261-288.

Conway, M.A., \& Rubin, D.C. (1993). The structure of autobiographical memory. In A.F. Collins, S.E. Gathercole, M.A. Conway, \& P.E. Morris (Eds.), Theories of Memory (pp. 103-137). Hove: Lawrence Erlbaum Associates.

Dalgleish, T., Spinks, H., Yierd, J., \& Kuyken, W. (2001). Autobiographical memory style in seasonal affective disorders and its relationship to future symptom remission. Journal of Abnormal Psychology, 110, 335-340.

Eysenck, M.W. (2009). Memory in childhood. In A. Baddeley, M. W. Eysenck, \& M.C. Anderson (Eds.), Memory (pp. 267-291). Hove: Psychology Press.

Goddard, L., Dritschel, B., \& Burton, A. (1996). Role of autobiographical memory in social problem solving and depression. Journal of Abnormal Psychology, 105, 609-616.

Hamilton, M. (1959). The assessment of anxiety states by rating. The British Journal of Medical Psychology, 32, 50-55.

Hamilton, M. (1960). A rating scale for depression. Journal of Neurology, Neurosurgery and Psychiatry, 23, 56-62.
Kolodner, J.L. (1983). Reconstructive memory: A computer model. Cognitive Science, 7, 281-328.

Kremers, I.P., Spinhoven, P., Van der Does, A.J.W., \& Van Dyck, R. (2006). Autobiographical memory in depressed and nondepressed patients with borderline personality disorder after long-term psychotherapy. Cognition and Emotion, 20, 448-465.

Kuyken, W., \& Brewin, C.R. (1995). Autobiographical memory functioning in depression and report of early abuse. Journal of Abnormal Psychology, 104, 585-591.

Kuyken, W., Howell, R., \& Dalgleish, T. (2006). Overgeneral autobiographical memory in depressed adolescent with, versus without, a reported history of trauma. Journal of Abnormal Psychology, 115, 387-396.

Leibetseder, M.M., Rohrer, R.R., Mackinger, H.F., \& Fartacek, R.R. (2006). Suicide attempts: Patients with and without an affective disorder show impaired autobiographical memory specificity. Cognition and Emotion, 20, 516-526.

Linton, M. (1975). Memory for real-world events. In D.A. Norman, \& D.E. Rumelhart (Eds), Explorations in Cognition (pp. 376-404). San Francisco: Freeman.

Linton, M. (1979). Real-world memory after six years: An in vivo study of very long term memory. In M.M. Grunenberg, P.E. Morris, \& R.N. Sykes (Eds), Practical Aspects of Memory (pp. 69-76). London: Academic Press.

Linton, M. (1982). Transformations of memory in everyday life. In U. Neisser (Ed.), Memory Observed: Remembering in Natural Contexts (pp. 77-91). San Francisco: Freeman.

Linton, M. (1986). Ways of searching and the contents of memory. In D.C. Rubin (Ed.), Autobiographical Memory (pp. 50-66). New York: Cambridge University Press.

Mackinger, H.F., Leibetseder, M.F., Kunz-Dorper, A.A., Fartacek, R.R., Whitworth, A.B., \& Feldinger, F.F. (2004). Autobiographical memory predicts the course of depression during detoxification therapy in alcohol depend men. Journal of Affective Disorders, 78, 61-65.

McNally, R.J., Lasko, N.B., Macklin, M.L., \& Pitman, R.K. (1995). Autobiographical memory disturbance in combat-related posttraumatic stress disorder. Behaviour Research and Therapy, 6, 112-128.

Moore, R.G., Watts, F.N., \& Williams, J.M.G. (1988). The specificity of personal memories in depression. The British Journal of Clinical Psychology, 27, 275-276.

Neisser, U. (1986). Nested structure in autobiographical memory. In D.C. Rubin (Ed.), Autobiographical Memory (pp. 71-80). New York: Cambridge University Press.

Norman, D.A., \& Bobrow, D.G. (1979). Descriptions: An intermediate stage in memory retrieval. Cognitive Psychology, 11, 107-123.

Peeters, F., Wessel, I., Merckelbach, H., \& Boon-Vermeeren, M. (2002). Autobiographical memory specificity and the course of major depressive disorder. Comprehensive Psychiatry, 5, 344-350.

Peterson, C. (1979). Uncontrollability and self-blame in depression: Investigation of the paradox in a college population. Journal of Abnormal Psychology, 88, 620-624.

Phillips, S., \& Williams, J.M. (1998). Cognitive impairment, depression and the specificity of autobiographical memory in the elderly. The British Journal of Clinical Psychology, 36, 341-347.

Pillemer, D.B. (1984). Flashbulb memories of the assassination attempt on President Reagan. Cognition, 16, 63-80.

Pillemer, D.B., \& White, S.H. (1989). Childhood events recalled by children and adults. In H.W. Reese (Ed.), Advance in Child Development and Behavior (Vol. 21, pp. 297-340). New York: Academic Press. 
Power, M., \& Dalgleish, T. (1997). Cognition and Emotion: From Order to Disorder. Hove: Taylor and Francis.

Raes, F., Hermans, D., Williams, J.M.G., Beyers, W., Brunfaut, E., Eelen, P. (2006). Reduced autobiographical memory specificity and rumination in predicting the course of depression. Journal of Abnormal Psychology, 115(4), 699-704.

Raes, F., Hermans, D., Williams, J.M.G., Demyttenaere, K., Sabbe, B., Pieters, G., \& Eelen, P. (2005). Reduced specificity of autobiographical memories: A mediator between rumination and ineffective social problem-solving in major depression. Journal of Affective Disorders, 87, 331-335.

Ramponi, C., Barnard, P.J., \& Nimmo-Smith, I. (2004). Recollection deficits in dysphoric mood: An effect of schematic models and executive mode? Memory, 12, 655-670.

Reiser, B.J., Black, J.B., \& Abelson, R.P. (1985). Knowledge structures in the organization and retrieval of autobiographical memories. Cognitive Psychology, 17(1), 89-137.

Reiser, B.J., Black, J.B., \& Kalamarides, P. (1986). Strategic memory search processes. In D.C. Rubin (Ed.), Autobiographical Memory (pp. 100-121). New York: Cambridge University Press.

Rubin, D.C., Wetzler, S.E., \& Nebes, R.D. (1986). Autobiographical memory across the lifespan. In D.C. Rubin (Ed.), Autobiographical Memory (pp. 202-224). New York: Cambridge University Press.

Ruíz-Vargas, J.M. (1991). Psicologia de la Memoria. Madrid: Alianza.

Schank, R.C. (1982). Dynamic Memory: A Theory of Reminding and Learning in Computers and People. New York: Cambridge University Press.

Searleman, A., \& Herrmann, D. (1994). Memory from a Broader Perspective. Singapore: McGraw-Hill International Editions.

Shallice, T. (1988). From Neuropsychology to Mental Structure. Cambridge: Cambridge University Press.

Skowronski, J.J., \& Walter, R.W. (2004). How describing autobiographical events can affect autobiographical memory. Social Cognition, 22, 555-590.

Spielberger, C.D., Gorsuch, R.C., Lushene, R.E., Vagg, P.R., \& Jacobs, G.A. (1983). Manual for the State-Trait Anxiety Inventory. Palo Alto: Consulting Psychologists Press.

Teasdale, J.D., \& Barnard, P.J. (1993). Affect, Cognition and Change: Remodelling Depressive Thought. Hove: Erlbaum.
Tulving, E. (1972). Episodical semantic memory. In E. Tulving, \& W. Donaldson (Eds), Organization of Memory (pp. 381-403). New York: Academic Press.

Watkins, E., \& Teasdale, J.D. (2001). Rumination and overgeneral memory in depression: Effects of self-focus and analytic thinking. Journal of Abnormal Psychology, 110, 353-357.

Watkins, E., \& Teasdale, J.D. (2004). Adaptive and maladaptive self-focus in depression. Journal of Affective Disorders, 82, 1-8.

Watkins, E., Teasdale, J.D., \& Williams, R.M. (2000). Decentring and distraction reduce overgeneral autobiographical memory depression. Psychological Medicine, 30, 911-920.

Watson, G.M.W., \& Dyck, D.G. (1984). Depressive attributional style in psychiatric inpatients: Effect of reinforcement and assessment procedures. Journal of Abnormal Psychology, 93, 312-320.

Wessel, I., Meeren, M., Peeters, F., Arntz, A., \& Merckelbach, H. (2001). Correlates of autobiographical memory specificity: The role of depression, anxiety and childhood trauma. Behavior Research Therapy, 39, 409-421.

Williams, J.M.G. (1992). The Psychological Treatment of Depression. (2nd ed.). London: Routledge.

Williams, J.M.G. (1996). Memory process in psychotherapy. In P. M. Salkovskis (Ed.), Frontiers of Cognitive Therapy (pp. 97-113). New York: Guilford Press.

Williams, J.M.G. (2004). Experimental cognitive psychology and clinical practice: Autobiographical memory as a paradigm case. In J. Yiend (Ed.), Cognition, Emotion and Psychopathology (pp. 251-269). Cambridge: Cambridge University Press.

Williams, J.M.G., \& Broadbent, K. (1986). Autobiographical memory in suicide attempters. Journal of Abnormal Psychology, 95, 144-149.

Williams, J.M.G., \& Dritschel, B.H. (1988). Emotional disturbance and the specificity of autobiographical memory. Cognition and Emotion, 2, 221-234.

Williams, J.M.G., \& Dritschel, B.H. (1992). Categoric and extended autobiographical memories. In D.C. Rubin, H. Spinnler, \& W.A. Wagennar (Eds), Theoretical Perspectives on Autobiographical Memory (pp. 391-410). The Netherlands: Kluver Academic Press.

Williams, J.M.G., Barnhofer, T., Crane, C., Hermans, D., Raes, F., Watkins, E., \& Dalgleish, T. (2007). Autobiographical memory specificity and emotional disorder. Psychological Bulletin, 133, $122-148$. 